\title{
Attempted Nose and Lip Replantation after Partial Animal Digestion
}

\author{
Trajan A. Cuellar, MB, BCh ${ }^{1}$ Catherine M. Westbom, $\mathrm{MS}^{1} \quad$ Dennis Orgill, MD, $\mathrm{PhD}^{1} \quad$ Julian J. Pribaz, $\mathrm{MD}^{2}$ \\ Edward J. Caterson, MD, $\mathrm{PhD}^{1}$ Simon G. Talbot, MD ${ }^{1}$
}

${ }^{1}$ Division of Plastic Surgery, Brigham and Women's Hospital, Boston, Massachusetts

${ }^{2}$ Division of Plastic Surgery, Morsani College of Medicine, Tampa General Hospital, Tampa, Florida

J Reconstr Microsurg Open 2018;3:e82-e86.
Address for correspondence Simon G. Talbot, MD, Department of Plastic Surgery, Brigham and Women's Hospital, 75 Francis Street, Boston, MA 02115 (e-mail: sgtalbot@bwh.harvard.edu).

\begin{abstract}
We report a case of a 71-year-old female patient who sustained a severe midface soft tissue avulsion injury from a family canine. The removed tissue was recovered from the canine's digestive tract and transferred to the hospital where emergent microvascular replantation was performed. The tissue survived for 72 hours, but then developed

Keywords

- replantation

- dog bite

- facial reconstruction vascular compromise. Despite aggressive revision of multiple anastomoses with extensive use of vein grafting, the replanted segment was lost. Reconstruction then proceeded along traditional lines with an acceptable cosmetic outcome and good functional outcomes.
\end{abstract}

Microvascular replantation is often the primary and best option after traumatic amputation. The face represents one of the most challenging regions to conventional reconstruction, and hence, replantation has an even greater benefit. The specialized sensory organs are concentrated in the head with specialized anatomic structures necessary for phonation, olfaction, oral intake, and nonverbal communication-all in close proximity. The nose, in particular, is the central prominent structure of the face and small variations in its shape have considerable impact on facial appearance and perception. Facial tissue is highly varied and includes mucosa, muscle, subcutaneous fat, skin, cartilage, and bone. This level of complexity is compounded with skin of varying thicknesses, contours, volumes, and shadowing that give unique appearances.

Understandably, limited institutional experience can be expected given the rarity of these injuries; however, the presence of advanced facial reconstruction and allotransplantation services can contribute to expertise and understanding of these injuries and reconstructions. ${ }^{1}$

This case of a microvascular replantation of the midface soft tissues required complex, multifactorial decision-making which often includes intraoperative assessment of suitable donor and recipient vessels. Our goal is to draw some generalizable conclusions on how to best manage these multifaceted cases.

\section{Clinical Case}

The patient is a 71-year-old female patient who received a devastating soft tissue avulsion of the midface soft tissues by a domestic, 1-year-old, male pit bull terrier canine. The avulsed tissue measured $10 \times 8 \mathrm{~cm}$ and included the nasal tip, soft triangles, columella, ala, lower lateral cartilages and portions of the upper lateral cartilages, a portion of the dorsum and lateral walls, nasal lining, as well as nasolabial grooves, upper lip with orbicularis oris, vermillion and mucosa to the level of the gingivobuccal sulcus (-Fig. 1A and B).

On arrival at the hospital, accompanying police had been unable to find the avulsed segment and believed it to have been swallowed by the dog. Knowing the complexity of reconstruction, the plastic surgery team requested an attempt to obtain this part from the animal by transfer to a local veterinary facility. The animal was euthanized, and the avulsed part found whole in the duodenum. It was rapidly washed and transported on ice to the hospital for inspection and possible replantation. The time from injury to surgery was approximately 6 hours. received

October 1, 2018

accepted

October 16, 2018
DOI https://doi.org/

10.1055/s-0038-1676606. ISSN 2377-0813.
Copyright $\odot 2018$ by Thieme Medical

Publishers, Inc., 333 Seventh Avenue, New York, NY 10001, USA.

Tel: +1(212) 584-4662.
License terms

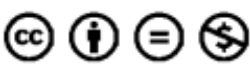



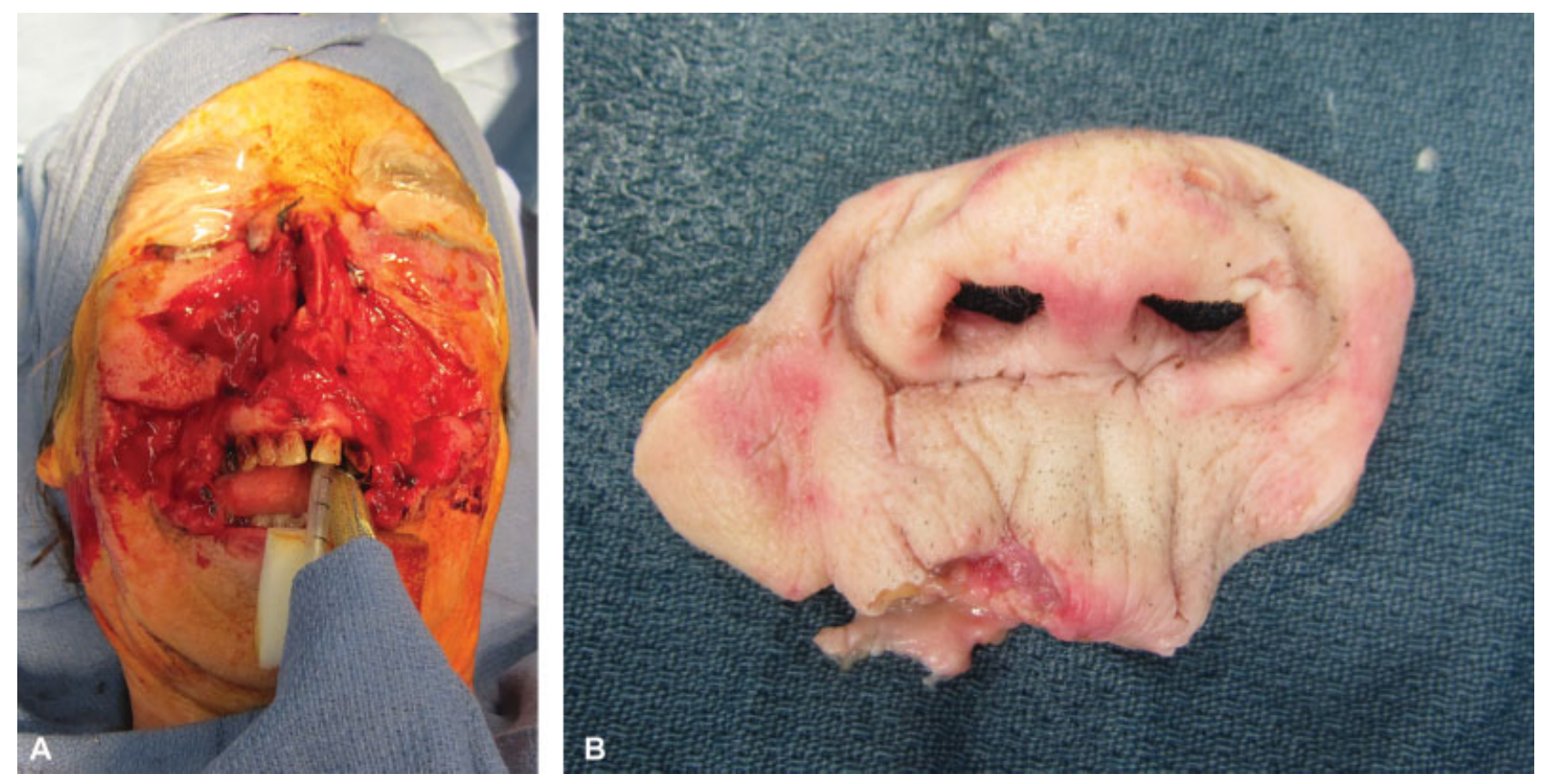

Fig. 1 (A) Facial appearance at time of presentation. (B) Amputated facial part after removal from dog digestive tract.

Three surgical teams were assembled. The first team performed the back-table dissection identifying suitable vessels on the amputated segment. Significant debridement and saline irrigation were performed. Bilateral angular arteries and a right angular vein were found and prepared for anastomoses. The second team prepared the recipient site, debriding devitalized tissue, and prepared vessels for anastomoses. Given the avulsion mechanism and length of damaged vessels, vein grafts were deemed to be needed, and these were obtained by the third team from the lower extremities.

Initially a branch of the left facial artery was found; however, due to the avulsion injury, inflow was noted to be inadequate even upon cutting back on the vessel. The left facial artery was then identified, and a vein graft was used to anastomose this to the amputated segment's submillimeter left angular artery. During the inset, the inflow was compromised and the anastomoses were revised several times to establish adequate flow. With flow restored, the right angular vein on the amputated segment and corresponding vein on the face were anastomosed. Loose inset was completed without difficulty. At this stage, in spite of all anastomoses being patent, the flap was noted to be mildly congested, likely due to an inflow-outflow mismatch, and leech therapy was initiated. Blood transfusions were undertaken to maintain a hematocrit above 21 while receiving leeches. The patient was kept intubated (-Fig. 2).

The initial postoperative course was unremarkable. However, at approximately 72 hours postoperative, the flap became pale and leeches failed to adhere. The patient was returned to the operating room where an arterial thrombus was noted. A Fogarty catheter was used to clear the vein graft and anastomoses were revised. Flow was noted to be well re-established.

Unfortunately, approximately 24 hours later an additional arterial thrombus necessitated microsurgical revision. This time, an additional vein graft was placed from the left superficial temporal artery to the dorsal aspect of the distal facial artery/angular artery vein graft, and flow was reestablished. Venous outflow appeared to be intact as evidenced by rapid re-perfusion, a Doppler-able venous signal, and the absence of congestion. After less than 24 hours, a further thrombosis of the arterial inflow recurred. Flow could not be resumed, and the decision was made to leave the segment in place to determine if any early neovascularization may maintain part of the flap.

By 7 days, the majority of the replanted segment had necrosed and the patient was taken to the operating room for debridement. The cheek tissue was undermined, and significant bilateral cheek advancement flaps were used to reduce the defect size to a portion of the upper lip and the entire nasal soft tissue including lining (-Fig. 3 ).

Eventual reconstruction was performed in stages over the next several months including further cheek advancement, mucoperiosteal nasal septal turnover flaps for nasal lining, a three-stage forehead flap for external nasal coverage, and nasolabial flaps for correction of nostril stenosis. The patient declined an Abbe flap (-Fig. 4).

\section{Discussion}

The facial dog bite scenario of which our case represents an extreme example has an estimated direct medical cost of $\$ 164.9$ million in the USA per year. ${ }^{2}$ Adults receive bites most commonly to the upper extremity (44\%) followed by the head and neck (28\%), while children are most commonly bitten in the head and neck region. ${ }^{2}$

The aesthetic and functional challenge of reconstructing the face with its level of societal prominence and soft tissue complexity is one of the most demanding in reconstructive 


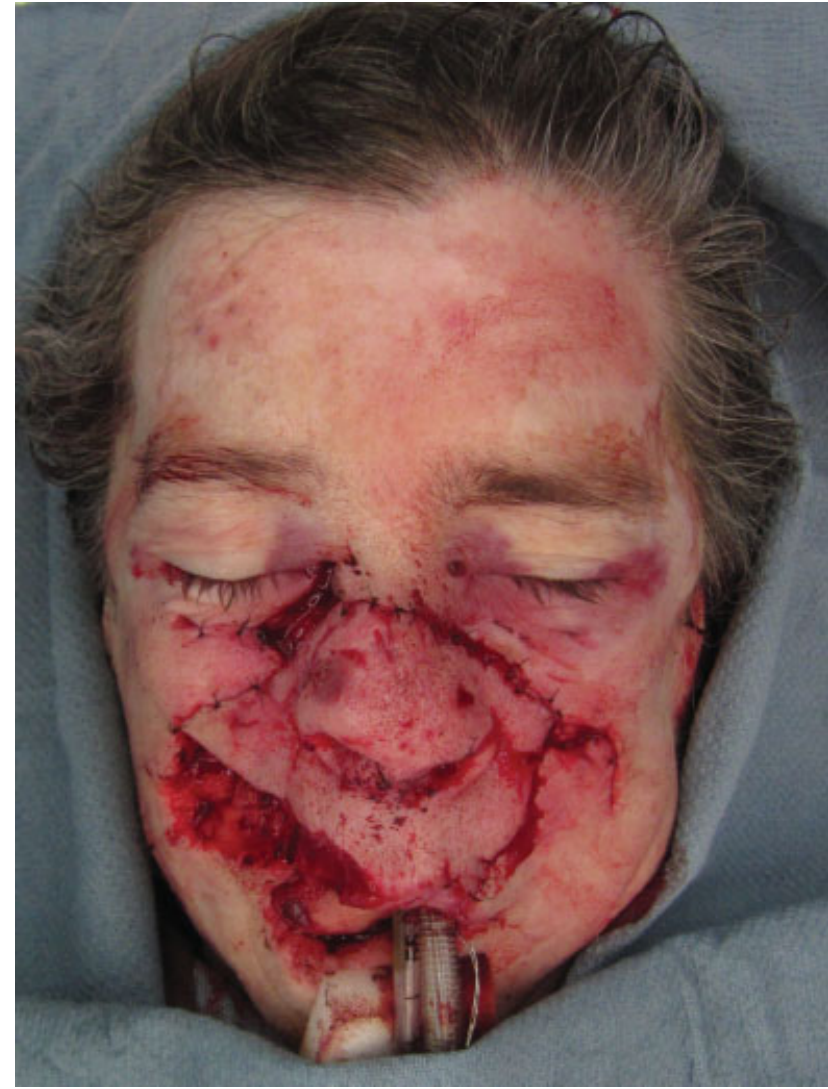

Fig. 2 Replanted segment.

surgery. Therefore, replantation of avulsed tissue, when possible, is often the first-choice option.

Grabb and Dingman reviewed composite graft replacement techniques in the early 1970s. They noted failure in all six patients reviewed. It is interesting to note that of their six cases, four were due to an attack by a mammal (one man, three dogs). ${ }^{3}$

The earliest case of microsurgical replantation of a facial segment occurred in 1975. A 3-year-old girl had near-complete loss of nose and upper lip as a result of a dog bite. The soft tissue segment measured $5 \times 3 \mathrm{~cm}$. A $1 \mathrm{~mm}$ superior labial artery was used for arterial anastomosis and a $0.3 \mathrm{~mm}$ subcutaneous vein was used for outflow. An early venous thrombosis was treated by return to the operating room for the revision of the anastomosis with survival of the majority of the replaced construction. ${ }^{4}$ This early attempt highlighted the importance of several factors in success or failure of microsurgical replantation. First is availability of microsurgical expertise in a timely manner. Cases have been reported in which injury time to operation is as little as 30 minutes or as long as 13 hours, with excellent cosmetic outcomes. ${ }^{5,6}$ Second is the size of the tissue that is replanted and the availability, number, type, and size of vessels. Replanted segments have ranged from to $2.5 \times 1 \mathrm{~cm}$ to $4 \times 5 \mathrm{~cm}$ with a single arterial anastomosis. ${ }^{7}$ Vessels have successfully been used for arterial anastomoses in the supermicrosurgery range from 0.3 to $0.7 \mathrm{~mm}^{8-11}$ Although the majority of anastomoses are artery to artery, cases of

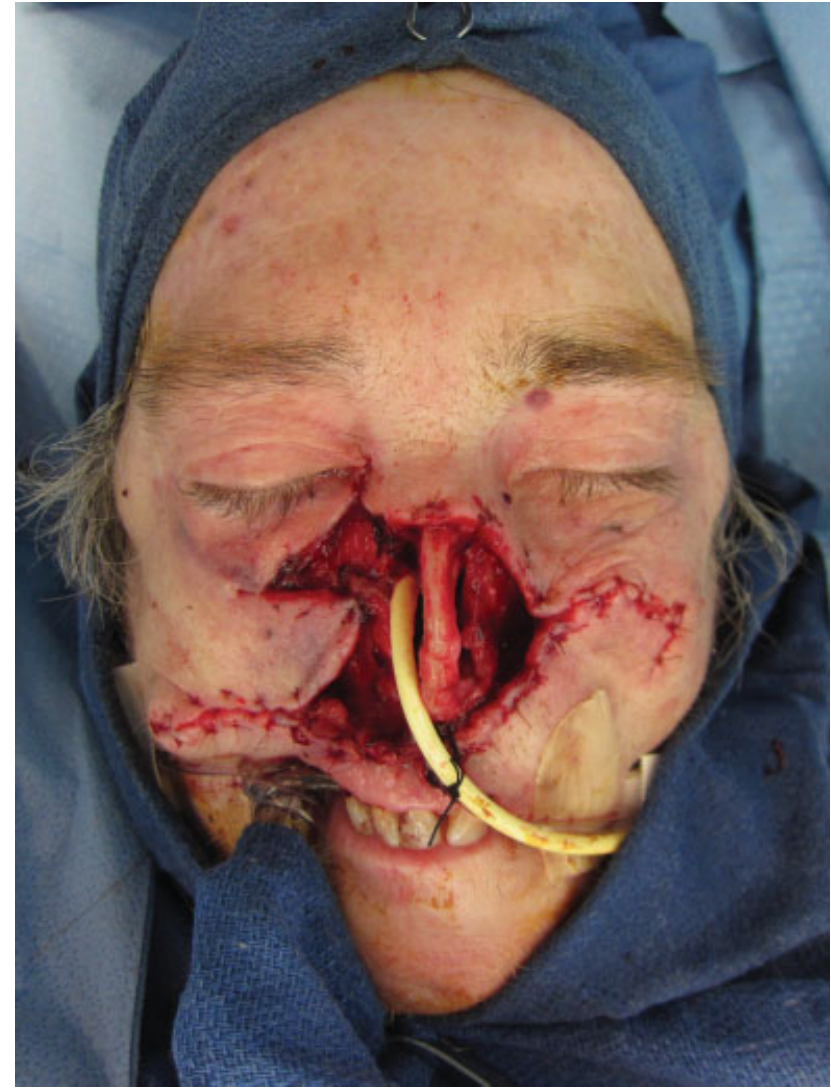

Fig. 3 Appearance after removal of amputated segment and first stage reconstruction.

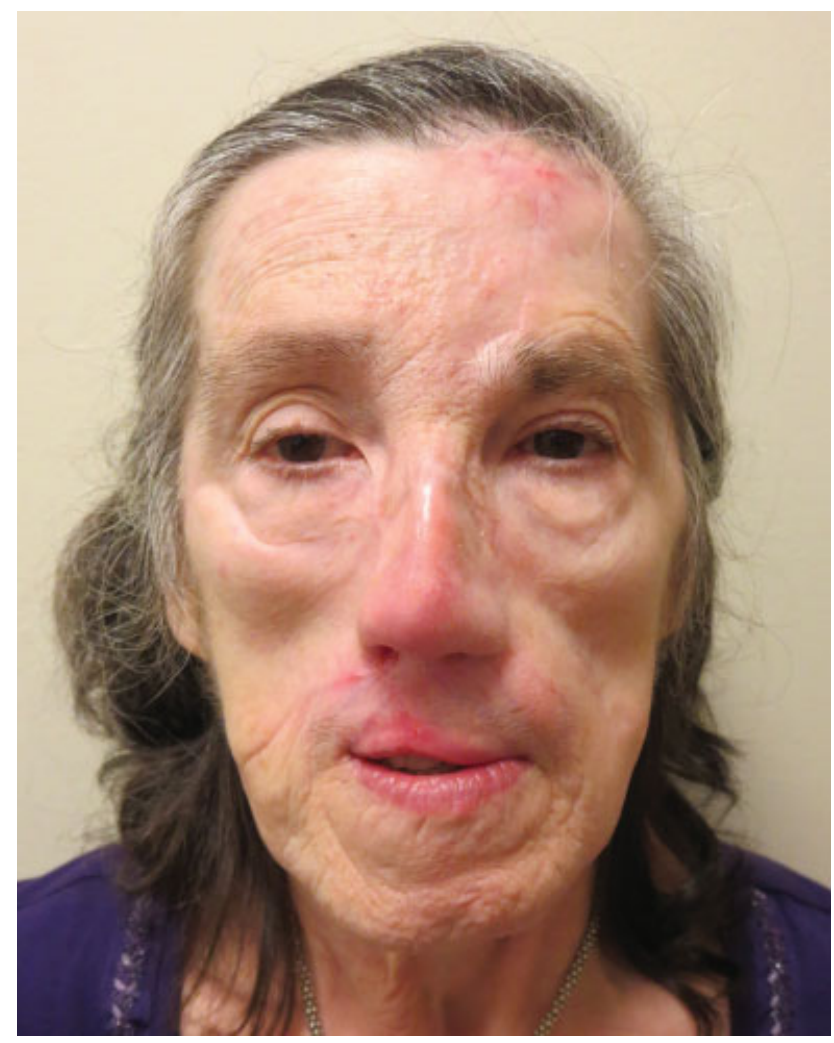

Fig. 4 Final appearance. 
successful revascularization of amputated segments by anastomosing an artery to an amputated segment vein have been reported, with veins ranging in size from 0.3 to $0.6 \mathrm{~mm} .^{10-12}$ Although venous-to-venous anastomoses are preferred, there are several examples of identified arteries with back bleeding being sutured to veins as a method of venous outflow, all with successful outcomes. ${ }^{9,13,14}$ Given the small size of vessels, vein grafting to generate tension-free anastomoses outside the zone of injury is often required, with the longest recorded at $13 \mathrm{~cm} .{ }^{6,9,13}$ The third issue is the near-universal problem of venous congestion even when venous anastomoses are performed. The majority of cases comment on venous congestion reaching critical levels and use of leeches, pin pricking, wound edge abrasion, skin abrasion, and topical anticoagulants. Several facilities were able to successfully navigate these venous outflow adjuncts as a primary source of venous drainage without a venous anastomosis even in tissue segments up to $4 \times 5 \mathrm{~cm} \cdot{ }^{5,7,15-17}$ A fourth factor may be the age of the patient. The youngest reported successful microvascular replantation of a nose is in an 18-month-old patient. ${ }^{11}$ Interestingly that case involved an arterial-to-venous anastomosis for arterial perfusion as no artery on the amputated segment could be identified. All pediatric cases with follow-up demonstrate appropriate growth of the replanted construct. ${ }^{11,18,19}$ A fifth consideration is mechanism of injury. These injuries are typically either a sharp slicing mechanism or a bite from either a dog or human. Bite injuries tend to have combined crush and avulsion components making them less amenable to replantation; but given the importance and uniqueness of the facial tissues, this is not universally considered a contraindication to attempted replantation. ${ }^{4-6,9,11,14,16,18,20}$ Incomplete amputation should not be completed as any avenue for venous drainage, even through small skin bridges, may ultimately be critical for replantation survival. ${ }^{16,21}$ The swallowing of a part by an animal is an uncommon event, minimally documented in the literature. We are aware of a single case similar to ours, but with a successful replantation result. One can assume that the degree of avulsion injury, potential chewing, and partial digestion will negatively affect success. ${ }^{18}$ We believe that our segment failed primarily due to vascular injury from the avulsion mechanism of injury, as evidenced by repeated vascular thrombi. Given that the part survived 72 hours and the vessels (which were significantly debrided) contained blood at the time of initial exploration, it seems less likely that the swallowing of the part and resultant stomach acidity directly caused necrosis.

Limitations of reviewing literature of this nature include publication bias in which cases with nonheroic outcomes are less commonly found in the literature, leading one to a false sense of what can be accomplished in a given clinical scenario. We believe the onus is on the plastic surgeon to attempt the best reconstruction possible.

\section{Conclusion}

For the reconstructive surgeon, facial soft tissue injuries can be as devastating as they are complex. The variety of tissue types, gentle curves, transitions, and highly visible nature of the injury are unmatched by any other anatomical region. The social impact of severe facial injuries such as these cannot be overemphasized. Certain fundamentals can be gleaned from the case presented and the available literature. First, timely transfer to a facility with microsurgical capability must be considered. Once the patient has arrived in the tertiary or quaternary care center, the replantation decision must be made in the context of the patient's overall condition. Second, the replanted tissue must be thoroughly assessed. Tissues that have undergone multiple crush events such as chewing may have vascular injury within the replanted segment and may be less likely to be successfully replanted. Third, precise anatomical knowledge and appreciation of the arterial supply and venous drainage are critical. Due to anatomical constraints, the orientation of the tissue is relatively fixed and vein grafts or alternate anastomoses (such as arterial-venous) are frequently required. ${ }^{22-24}$ Fourth, the use of venous drainage adjuncts (such as leech therapy, injection of anticoagulants, skin pricking, skin abrasion with anticoagulant wipes, or partial inset with exposed fresh wound edges) is very commonly necessary.

No reconstructive method can restore form and function as precisely as replacement of native tissue. As such, when possible and relatively safe, every effort should be made to attempt microsurgical reconstruction before resorting to more traditional methods of reconstruction.

\section{Conflict of Interest}

None.

\section{Acknowledgments}

We would like to thank the numerous medical students and residents who assisted in the care of this patient during her multiple operations.

\section{References}

1 Pomahac B, Lengele B, Ridgway EB, et al. Vascular considerations in composite midfacial allotransplantation. Plast Reconstr Surg 2010;125(02):517-522

2 Cameron O, Al-Himdani S, Oliver DW. Not a plastic surgeon's best friend: dog bites an increasing burden on UK plastic surgery services. J Plast Reconstr Aesthet Surg 2017;70(04):556-557

3 Grabb WC, Dingman RO. The fate of amputated tissues of the head and neck following replacement. Plast Reconstr Surg 1972; 49(01):28-32

4 James NJ. Survival of large replanted segment of upper lip and nose. Case report. Plast Reconstr Surg 1976;58(05):623-625

5 Flores RL, Bastidas N, Galiano RD. Successful replantation of an amputated nose after dog bite injury. Otolaryngol Head Neck Surg 2007;136(02):326-327

6 Gilleard O, Smeets L, Seth R, Jones ME. Successful delayed nose replantation following a dogbite: arterial and venous microanastomosis using interpositional vein grafts. J Plast Reconstr Aesthet Surg 2014;67(07):992-994

7 Kayikçioğlu A, Karamürsel S, Keçik A. Replantation of nearly total nose amputation without venous anastomosis. Plast Reconstr Surg 2001;108(03):702-704

8 Hammond DC, Bouwense CL, Hankins WT, Maxwell-Davis GS, Furdyna J, Capraro PA. Microsurgical replantation of the amputated nose. Plast Reconstr Surg 2000;105(06):2133-2136, quiz 2137, discussion 2138 
9 Tajima S, Ueda K, Tanaka Y. Successful replantation of a bitten-off nose by microvascular anastomosis. Microsurgery 1989;10(01):5-7

$10 \mathrm{Kim}$ S, Jeong H, Choi TH, Kim JS. Successful re-plantation of an amputated nasal segment by supermicrosurgery: a case report and review of the literature. J Plast Reconstr Aesthet Surg 2010;63 (04):e380-e383

11 Marsden NJ, Kyle A, Jessop ZM, Whitaker IS, Laing H. Long-term outcomes of microsurgical nasal replantation: review of the literature and illustrated 10-year follow-up of a pediatric case with full sensory recovery. Front Surg 2015;2:6

12 Yao JM, Yan S, Xu JH, Li JB, Ye P. Replantation of amputated nose by microvascular anastomosis. Plast Reconstr Surg 1998;102 (01):171-173

13 Jeng SF, Wei FC, Chen PK. Successful replantation of an amputated nasal tip by microvascular anastomosis. Plast Reconstr Surg 1991;87(06):1118-1120

14 Sun W, Wang Z, Qiu S, Li S. Successful microsurgical replantation of the amputated nose. Plast Reconstr Surg 2010;126(02):74e-76e

15 Niazi Z, Lee TC, Eadie P, Lawlor D. Successful replantation of nose by microsurgical technique, and review of literature. Br J Plast Surg 1990;43(05):617-620

16 Stillaert FB, Roche N, Zeltzer A, Monstrey S. Artery only microanastomosis in nose replantation: a report of two cases. J Plast Reconstr Aesthet Surg 2012;65(04):513-516
17 Akyürek M, Safak T, Keçik A. Microsurgical revascularization of almost totally amputated alar wing of the nose. Ann Plast Surg 2004;53(02):181-184

18 Stupka I, Dvorak Z, Vesely J, Novak P, Perrotta RE, Lombardo GA Reconstruction of a nose bitten and eaten by a dog: a ten-year follow-up of a bitten-off nose replantation performed on an eleven-year-old boy. Ann Plast Surg 2015;75(06):585-587

19 Ueda K, Nuri T, Okada M, Maeda S. 28 years' follow-up of bittenoff nose replantation performed in a 9-year-old girl. Plast Reconstr Surg 2014;133(06):904e-905e

20 Øregaard JS, Lang CL, Venzo A. Partial salvage of avulsed tissue after dog bite. Ann R Coll Surg Engl 2016;98(02):e22-e25

21 Pereira O, Bins-Ely J, Lobo GS, Lee KH, Eickhoff D. Successful replantation of an almost-amputated nose. Plast Reconstr Surg 2010;125(06):249e-251e

22 Pilsl U, Anderhuber F. The external nose: the nasal arteries and their course in relation to the nasolabial fold and groove. Plast Reconstr Surg 2016;138(05):830e-835e

23 Cotofana S, Steinke H, Schlattau A, et al. The anatomy of the facial vein: implications for plastic, reconstructive, and aesthetic procedures. Plast Reconstr Surg 2017;139(06): 1346-1353

24 Onishi S, Imanishi N, Yoshimura Y, et al. Venous drainage of the face. J Plast Reconstr Aesthet Surg 2017;70(04):433-440 